\title{
Introduction to the Indiana Climate Change Impacts Assessment: overview of the process and context
}

\author{
Melissa Widhalm ${ }^{1}$ (D) J Jeffrey S. Dukes ${ }^{1,2,3}$ (D) \\ Received: 15 October 2020 / Accepted: 29 October 2020 / Published online: 20 November 2020 \\ (C) Springer Nature B.V. 2020
}

\begin{abstract}
The Indiana Climate Change Impacts Assessment (IN CCIA) is a collaborative effort to provide professionals, decision makers, and the public with information about how climate change affects state and local interests throughout Indiana, USA. This assessment effort has three interrelated goals: (1) analyze and document the best available climate change impacts research, (2) develop and maintain a network of stakeholders and experts, and (3) start a dialog about climate change throughout Indiana. The project adopted a process that prioritized stakeholder engagement, re-envisioned traditional dissemination approaches, and that had limited state government involvement, setting the IN CCIA apart from most other state climate assessments (SCAs) in the USA. This overview describes the motivations, principles, and processes that guided the IN CCIA development, explores how Indiana's approach compares with those of other SCAs, and briefly summarizes the papers presented in this special issue. As interest in SCAs grows in noncoastal and politically conservative locations, the IN CCIA serves as one example of how a bottom-up assessment with limited funding can deliver credible climate science to diverse stakeholder groups in the absence of state-level mandates or direction and attract public attention over an extended period of time.
\end{abstract}

Keywords Engaged research · Extreme weather · Midwest · State climate assessment

This article is part of a Special Issue on "The Indiana Climate Change Impacts Assessment" edited by Jeffrey Dukes, Melissa Widhalm, Daniel Vimont, and Linda Prokopy

Supplementary Information The online version contains supplementary material available at https://oi. org/10.1007/s10584-020-02928-7.

Jeffrey S. Dukes

jsdukes@purdue.edu

1 Purdue Climate Change Research Center, Purdue University, West Lafayette, IN, USA

2 Department of Forestry and Natural Resources, Purdue University, West Lafayette, IN 47907, USA

3 Department of Biological Sciences, Purdue University, West Lafayette, IN 47907, USA 


\section{Introduction}

As human activities trap increasing amounts of heat in Earth's oceans and atmosphere (USGCRP 2017; IPCC 2014), a growing number of global and national reports describe trends in past weather data, provide projections of future climate, and assess how these changes affect natural and human-built systems. These broad climate assessments provide valuable insights about the scope and scale of threats facing the world, but they lack the locally relevant information required to support state and community climate adaptation and mitigation actions (Kirchhoff et al. 2019).

To fill this information gap for local decision makers and residents, 27 different US states had completed at least 50 state climate assessments (SCAs) by 2020, with three additional states conducting their first (Fig. 1). At least ten states have undertaken more than one assessment, with the earliest SCAs dating back to 1989. The motivation driving these assessments (mandated by state governments or conducted in alignment with an organization's mission without a mandate), their scope, and the groups(s) responsible for leadership and oversight, have varied by location (Supplemental Table 1). The state-level scale of analysis recognizes that, while climate change is not constrained by political boundaries, state and local decision makers must work within them.

There are no established standard practices for conducting state or national climate assessments. However, several assessment teams have outlined their experiences with conducting assessments (NAS 2019), engaging stakeholders in the climate assessment process (Cloyd et al. 2016; Galford et al. 2016), and evaluating similarities and differences among climate assessments (Kirchhoff et al. 2019). From these accounts, it is clear that SCAs are uniquely positioned to provide relevant, actionable information at local scales.



Fig. 1 Status of state climate assessments (SCAs) in the USA as of 2020. A key to the state abbreviations and details about the individual SCAs is provided in Supplemental Table 1 
SCAs serve to generate primary data sources, build networks of experts, and inform stakeholders (Galford et al. 2016). SCAs provide science from local trusted sources, and they serve as a connection point between experts and decision makers (Kirchhoff et al. 2019). Finally, similar to national-scale assessments, SCAs can become useful and influential decision tools when they are perceived by stakeholders as being credible, legitimate, and salient (Cash et al. 2003; Lemos et al. 2012; Kirchhoff et al. 2019).

Here, we summarize the process used to conduct and disseminate the Indiana Climate Change Impacts Assessment (IN CCIA) and place the IN CCIA in the context of other SCAs. We also provide a brief description of, and context for, the additional papers in this special issue, which served as the technical papers supporting the IN CCIA.

\section{Indiana's physical and social climate}

Located in the central USA, the state of Indiana has a hot-summer humid continental climate, with humid subtropical climate conditions in the southern reach of the state. Indiana experiences four distinct seasons with large temperature extremes and year-round precipitation. Warm season precipitation is dominated by convective storms that can bring threats of tornadoes and extreme wind. Cold season precipitation is driven by large-scale midlatitude systems, providing a mix of snow and rain in the north and predominantly rain in the south.

From 1895 to 2019 , Indiana's annual average temperature warmed by $0.72{ }^{\circ} \mathrm{C}$ and annual precipitation increased by $165 \mathrm{~mm}$ (16\%; NOAA 2020). Future climate projections estimate that average annual conditions during the period $2041-2070$ will warm $2.79-3.33{ }^{\circ} \mathrm{C}$ with $6-$ $8 \%$ more precipitation, relative to the period 1971-2000 (Hamlet et al. 2019). As highlighted within this Special Issue, a shifting climate has far-reaching consequences for Indiana's residents, social and natural systems, and economy.

Indiana's Gross State Product (GSP) was \$332bn in 2019, ranking 38th out of all 50 states (BEA 2019). The top three sectors contributing to Indiana's GSP are manufacturing (30\%), real estate (11\%), and health care (9\%) (IBIS World 2019). The top sectors contributing to individual employment are manufacturing (557 k jobs), health care (451 k jobs), and retail trade (393 k jobs) (IBIS World 2019).

Agriculture and forestry, while contributing just over 1\% to Indiana's GSP (BEA 2019), use the majority of land area in the state and are highly sensitive to weather and climate extremes. Indiana is a top contributor to US corn and soybean production and also produces several specialty crops (such as blueberries, processing tomatoes, and watermelon) and livestock (such as hogs, chickens, and eggs) (USDA NASS 2017).

While many economic sectors face some level of increased risk as weather and climate extremes intensify, there are other socio-economic and political factors that will contribute to the state's overall climate change vulnerability. Indiana ranks 41 st in the country for overall health rankings, with high prevalence of smoking, obesity, and physical inactivity; poor air quality, and very low public health funding (America's Health Rankings 2019). Aging infrastructure and low financial investments puts added strain on the state's roads, bridges, and dams along with drinking and wastewater facilities (ASCE 2017).

Despite observed climate trends and existing vulnerabilities, public perceptions about climate change are at odds with scientific conclusions. While nearly all climate scientists conclude that climate change is happening (Cook et al. 2016), public opinion polls show the percent of Indiana residents who understand climate change is happening to be between $64 \%$ 
to 79\% (Howe et al. 2015; Daugherty et al. 2020; Houser et al. 2020). Additionally, scientific consensus about climate change is not recognized by one third of Indiana residents, and among Indiana residents who understand that the climate is changing, approximately half do not know or have little/no concern about climate change personally affecting them (Houser et al. 2020).

Many studies have revealed strong connections between political affiliations and climate change risk perceptions (see Santos and Feygina 2017 for an in-depth review), with people who identify as Republican or politically conservative having significantly increased skepticism about climate change science than those identifying as Democratic or politically liberal. Indiana has had Republican governors since 2005. A Republican majority has ruled in the Indiana House of Representatives since 2011 and the Indiana Senate since 1979 (Ballotpedia 2020).

\section{The Indiana Climate Change Impacts Assessment (IN CCIA)}

\subsection{Background}

The first climate change assessment for Indiana (PCCRC 2008) was completed in 2008 by faculty at Purdue University at the request of US Senator Richard Lugar, who at the time, was preparing to vote on the Lieberman-Warner Climate Security Act of 2007-2008. Purdue experts were given only a few weeks from the time of the request to produce the climate report, which was designed primarily to inform Indiana's members of the US Congress about the potential for climate change to affect the state. The climate assessment outlined potential impacts assuming no action was implemented to curb global greenhouse gas emissions. It included quantitative analysis based on published and unpublished data from Purdue University researchers along with qualitative expert opinions. The report concluded that Indiana is likely to experience more extreme heat, thunderstorms, and winter and spring rainfall, which will have subsequent effects on human health, crop production, soil quality, and wildlife habitats. Scientists also noted the potential for agricultural lands to offset carbon emissions and the resulting co-benefits of carbon sequestration practices. The Lieberman-Warner Climate Security Act of 2007-2008 ultimately failed to pass the US Senate, with Senator Lugar voting against it.

The 2008 assessment was overseen by the Purdue Climate Change Research Center (PCCRC), a faculty-led center established in 2004 to facilitate interdisciplinary climate change research, education, and engagement. The PCCRC provided open access to the 2008 Purdue report (PCCRC 2008) on its website, and for nearly a decade, it remained the only statewide review of climate risks for Indiana.

In the years following the 2008 Purdue report, several international, national, regional, and sector-based assessments examined how projected changes in climate would affect natural and human-built systems. This growing body of research resulted in frequent inquiries to the PCCRC for updated state-level climate impact information. Nearly a decade later, in 2017, the PCCRC embarked on a new effort, called the Indiana Climate Change Impacts Assessment (IN CCIA), to fulfill these information requests. The IN CCIA puts Indiana in a group of just 10 states that have completed more than one SCA as of 2020. Six SCAs have been conducted in California with all but one fulfilling a state mandate and including the earliest SCA on record in the USA. 
Pennsylvania has four completed reports, all of which resulted from a state mandate. Oregon (state mandated) and Maine (not mandated) both have three completed reports. The remaining six states all have two assessments with a mix of motivations driving the SCAs.

\subsection{Approach and guiding principles}

The IN CCIA was designed to provide an updated, in-depth look at the many ways the changing climate is expected to affect state and local interests, such as public health, agriculture and forestry, tourism and recreation, water resources, and electricity supply and demand. The assessment process was designed around the guiding principle that usable climate science must be perceived as credible, legitimate, and salient (Cash et al. 2003; Lemos et al. 2012), making stakeholder engagement and diverse content expertise a high priority.

The IN CCIA had three interrelated goals: (1) analyze and document the best available climate change impacts research, (2) develop and maintain a network of stakeholders and experts, and (3) start a dialog about climate change across the state.

Unlike many other SCAs, the IN CCIA is a mission-based, bottom-up assessment effort, conducted in the absence of a state government mandate or policy and with no external funding. The PCCRC provided funding to support coordination and dissemination, while expert and stakeholder contributions were provided in-kind. Among other SCAs in the US, about half have been conducted to fulfill a state mandate while half were conducted in the absence of a mandate (mission-based; Supplementary Table 1). All except ten SCAs clearly included guidance or notable involvement from state agency personnel and/or elected state officials, with Indiana's two SCAs both having no deliberate involvement from top state officials.

\subsection{Stakeholder engagement}

Stakeholder engagement, communication, and partnership building are essential for ensuring the usefulness, usability, and acceptance of climate information (McNie 2013; Cloyd et al. 2016). Therefore, the IN CCIA process prioritized stakeholder involvement at all stages of the assessment. We hoped that this process would lead to a more useful set of assessment products, increase buy-in and support from the intended audience, increase awareness about the IN CCIA, and help Indiana residents identify ways that climate change affects them and their communities. While this engaged approach follows "best practice," few other SCAs have implemented it. According to Kirchhoff et al. (2019), which included the IN CCIA in the analysis, "only 2 of the 14 assessments [they reviewed] invested heavily in engagement and communication in addition to knowledge creation."

We broadly define stakeholders as anyone who is interested in, or likely affected by, the information included in the IN CCIA. The target audience for the IN CCIA engagement and dissemination efforts was identified as decision makers, policy makers, professionals, and organized citizens' groups. To accommodate a wide range of preferred levels of interest and involvement among stakeholders, the IN CCIA identified an engagement spectrum that used multiple approaches to engage and inform (Table 1).

Pre-assessment engagement was essential for shaping the assessment goals, working group topics, and assessment content. PCCRC staff gathered stakeholder feedback at several listening sessions organized with assistance from members of the IN CCIA Steering Committee. Feedback was also collected during dedicated information sessions at professional 
Table 1 Engagement tactics used before, during, and after the Indiana Climate Change Impacts Assessment

\begin{tabular}{ll}
\hline Time period & Engagement tactics \\
\hline Ongoing & $\begin{array}{c}\text { Maintain regular communication with } \\
\text { monthly newsletters, website, social media } \\
\text { Formal and informal feedback opportunities at } \\
\text { listening sessions, small group meetings, and symposia }\end{array}$ \\
$\begin{array}{l}\text { Pre-assessment } \\
\text { Suring assessment }\end{array}$ & Community briefings and events, media resources, pursue new partnerships \\
\hline
\end{tabular}

organization meetings, and during small group meetings with non-profits, state and local agency staff, and university staff. Additional input was solicited from individuals by phone and email.

The intent of the pre-assessment engagement was to gather formative and practical input, rather than research quality results, from stakeholders across diverse sectors reflective of topics covered within other SCAs (see Supplemental Table 1). Stakeholders who provided preassessment feedback were employed in a variety of fields including public health, public works, environmental management, urban planning, agriculture, disaster management, energy planning, and transportation. Input was provided around three essential questions: (1) Assessment scope-What topics and future time periods would you expect to be covered in a statewide climate change impacts assessment? (2) Sector scope-What climate impacts are of concern to your sector, now or in the future? (3) Information scope-What information sources do you find useful and trustworthy?

While the assessment reports were under development, PCCRC staff assembled stakeholder review panels for each topic-based working group. Each stakeholder review panel consisted of 3-5 professionals, often representing related interest groups, who were given the opportunity to provide comments on the report outline and a near final draft of the full technical report for a specific topic-based working group. Stakeholder reviewers were not screened based on their level of understanding about climate change science or their political leanings. Participants were identified based on recommendations from sector/organizational leaders, IN CCIA authors and Steering Committee members, and/or self-signups at stakeholder feedback events. Their input was used to identify information gaps and identify specific concepts or graphics within the report that could be difficult for a non-technical audience to understand. This input played an important role in shaping the key messages and communication strategies implemented within the IN CCIA reports.

\subsection{Report development}

SCAs can enhance their saliency, legitimacy, and credibility with stakeholders by including local experts and trusted organizations in their assessment research and outreach (Kirchhoff et al. 2019). Therefore, unlike the 2008 Purdue report, the IN CCIA sought contributions from experts at over a dozen organizations within Indiana, including universities, state agencies (extremely limited), local agencies, and other non-profit organizations. In total, the IN CCIA included contributions from about 100 experts.

Coordination and oversight of the IN CCIA was provided by PCCRC staff. A Steering Committee was convened to provide input on strategic planning, stakeholder engagement, and report development and dissemination. Based on pre-assessment feedback and analysis of 
other SCAs (see Supplemental Table 1), ten sector-based topics were identified and "technical working groups" were planned around these themes. A lead author was identified for each working group topic, and the lead worked closely with the PCCRC and IN CCIA Steering Committee to identify and recruit a team of expert contributors.

Each working group was tasked with developing a "technical report" in the format of a journal article, which was then reviewed for relevance by a panel of stakeholders and submitted for peer review and inclusion in this special issue. Working groups determined the scope and content of each report based on a combination of pre-assessment stakeholder input, existing published research, and available expertise. A few of the working groups were also able to conduct and include new research in their technical reports by leveraging ongoing work and resources. No funding was available from the IN CCIA to conduct additional work to fill research gaps, which meant that some stakeholder requests, such as the inclusion of economic impacts, were not possible to fulfill.

The technical reports provide the basis for a series of "non-technical" IN CCIA reports cowritten by PCCRC staff and a science writer in coordination with each working group, and targeted at stakeholders and the general public. The non-technical reports (referred to as the IN CCIA reports) are disseminated widely (see next section); they include minimal technical detail, many easy-to-read graphics, and a moderate number of key references.

\subsection{Dissemination and impact}

The IN CCIA reports have been released one at a time, starting in early 2018, with new reports initially released about every 1-3 months. This approach was organized intentionally to make sure information consumers would receive a steady stream of content, in smaller pieces, as opposed to a deluge of climate impact information. As an added benefit, a staggered assessment rollout helped accommodate the limited time and personnel resources available within a voluntary assessment. We believe the IN CCIA has been the only SCA to use this type of dissemination approach.

To reach a variety of media markets and communities, each report release included an in-person community briefing at a different location around the state. These briefings were organized in partnership with a local stakeholder organization as a way to increase engagement and credibility. Prior to each community briefing, PCCRC staff personally contacted dozens of relevant stakeholders (local and statewide) to inform them about the IN CCIA, provide details about the upcoming release, and invite them to attend. A follow-up email was sent after each event with a press release, a video summary of the event, and a link to view the report online.

Following each report release, PCCRC staff conducted a 2-week social media campaign, highlighted the report findings in the IN CCIA newsletter, spoke at community events statewide, and gave interviews to news organizations developing stories for print and online publications. PCCRC staff also developed supplemental resources, such as fact sheets and sample presentations, to support partnering organizations in their efforts to disseminate the IN CCIA reports.

Formal evaluation of the IN CCIA was beyond the scope of this effort. However, PCCRC staff monitored a variety of basic metrics to provide a general indication of the IN CCIA's influence. Quantitative metrics included web traffic, report downloads, speaking engagements attended, and media mentions. Qualitative metrics included submitted testimonials, use of IN CCIA data in spin-off products, and new partnerships developed. 


\section{Overview of papers in this special issue}

As described in the previous section, the IN CCIA reports were primarily based on the technical papers written by the IN CCIA working groups and found within this special issue. We summarize these papers here:

Impacts of Climate Change on the State of Indiana: Ensemble future projections based on statistical downscaling (Hamlet et al. 2019) provides the foundational climate projections for the IN CCIA. Hamlet et al. (2019) use an ensemble of 10 downscaled climate model simulations to examine projected climate changes for two greenhouse gas concentration scenarios during three future time periods. From these projections, they characterize shifts in annual and seasonal temperature and precipitation, climate extremes, heating and cooling demand, snowfall, and the length and timing of the growing season.

An assessment of the potential impacts of climate change on the freshwater habitats of Indiana, U.S.A. (Höök et al. 2019) examines the direct and indirect ecological consequences of shifting temperature and rainfall patterns. Höök et al. (2019) describe anticipated changes to physico-chemical and habitat conditions across Indiana and expected responses of aquatic biota. They consider interactions between climate change and other anthropogenic stressors and consider the potential for evolutionary adaptation to mitigate climate impacts.

An integrated assessment of the potential impacts of climate change on Indiana forests (Phillips et al. 2019) looks at end-of-century projections of tree habitat suitability, resulting effects on forest composition and ecosystem services, and implications for forest management. Phillips et al. (2019) also discuss impacts to wildlife, implications for tree growth and harvest, and potential changes in biological stressors such as invasive plants and pests.

Projected Climate Change Impacts on Indiana's Energy Demand and Supply (Raymond et al. 2019) and Projecting Urban Energy Demand in Indiana for 2050 and 2080 (Singh and Wachs 2020) both provide insights on Indiana's future energy landscape. Raymond et al. (2019) examine the effect of climate change on statewide energy demand and supply and model how different energy policies could affect the future energy supply mix in Indiana. Singh and Wachs (2020) focus specifically on changes in urban residential and commercial heating and cooling demand at mid- and late-century across Indiana.

Implications of climate change for managing urban green infrastructure in Indiana (Reynolds et al. 2019) examines the ways urban green infrastructure (UGI) is affected by climate change and strategies for coping with change. UGI reviewed in this paper includes urban forests, urban gardens, green drainage systems, urban prairies, and urban lawns.

Climate change impacts on human health at an actionable scale: A state-level assessment of Indiana, USA (Filippelli et al. 2020) looks at the human health risks and outcomes associated with warming temperatures, reduced air and water quality, and increased exposure to vector-borne and water-related diseases. Filippelli et al. (2020) also discuss climate change implications for food and food safety.

Climate change impacts and strategies for adaptation for water resource management in Indiana (Cherkauer et al. in prep) uses an ensemble of large-scale hydrology models to investigate how projected climate change would affect future water movement and storage across Indiana. Cherkauer and colleagues provide a look at infiltration, soil water, evapotranspiration, streamflow, and cold-season processes in a changing climate.

Agricultural Impacts of Climate Change in Indiana and Potential Adaptations (Bowling et al. 2020) analyzes the direct, indirect, and aggregate effects of climate change on agronomic crops, horticultural crops, livestock and poultry, and soil and water 
resources. Bowling and co-authors also discuss adaptation measures that are currently available to cope with impacts to Indiana's agricultural systems.

Indiana Climate Change Impact Assessment: Tourism and Outdoor Recreation (Day et al. in prep) explains how climate change will impact the timing, enjoyment, and safety of outdoor activities, with cascading effects on both visitors and the businesses serving the tourism industry. Day and colleagues also provide a discussion of risk management, resilience, and adaptation within the recreation and tourism sector.

\section{Conclusions}

The IN CCIA is a bottom-up project with limited funding that brings credible climate change information to a variety of stakeholders. The assessment highlights climate change impacts in a politically conservative state that has seen little state-level attention to the issue. While the motivation for conducting the IN CCIA was mission-based and similar to many other SCAs, the Indiana assessment employed several unique approaches for ensuring the saliency, legitimacy, and credibility of research and outreach. We share the background, motivation, goals, and processes for conducting the IN CCIA not just to provide context to the articles appearing in this special issue, but also to provide an example for other sub-national scale teams interested in conducting local climate assessments. There are no established guidelines for conducting SCAs, but the need for SCAs is growing as local decision makers face increasing pressure and urgency to adapt to and mitigate climate change. We encourage other teams to also share their experiences so that standard practices and best practices for designing local assessments can be identified.

Acknowledgments We thank all of the content experts, stakeholders, and steering committee members who volunteered their expertise and time to contribute to the Indiana Climate Change Impacts Assessment (IN CCIA). The IN CCIA is organized and financially supported by the Purdue Climate Change Research Center.

Authors' contributions JSD and MW conceived the paper. MW wrote the paper with input from JSD. Both authors revised the paper.

Funding The Purdue Climate Change Research Center provided financial support for this work.

Data availability N/A

\section{Compliance with ethical standards}

Conflict of interest The authors declare that they have no competing interests.

Code availability N/A

\section{References}

America's Health Rankings (2019) America's Health Rankings analysis of America's Health Rankings composite measure. United Health Foundation. https://www.americashealthrankings. org/explore/annual/measure/Overall/state/IN. Accessed 11 Nov 2020 
ASCE (2017) 2017 Infrastructure Report Card. American Society of Civil Engineers, Reston, VA. https:/www. infrastructurereportcard.org/. Accessed 02 Oct 2020

Ballotpedia (2020) Indiana State Senate. https://ballotpedia.org/Indiana_State_Senate. Accessed 07 October 2020

BEA (2019) Local area gross domestic product, 2018. Bureau of Economic Analysis, Suitland, MD. https://www.bea.gov/data/gdp/gdp-county-metro-and-other-areas. Accessed 02 Oct 2020

Bowling L, Beckerman J, Brouder S, Buzan J, Cherkauer KA, Doering O, Dukes JS, Ebner P, Frankenberger J, Gramig B, Kladivko E, Lee C, Volenec J, Weil C (2020) Agricultural impacts of climate change in Indiana and potential adaptations. Clim Chang

Cash D, Clark WC, Alcock F, Dickson NM, Eckley E, Jäger J (2003) Salience, credibility, legitimacy and boundaries: linking research, assessment and decision making. John F. Kennedy School of Government, Harvard Univ, Cambridge, MA. Faculty Working Paper RWP02-046, 25 pp

Cherkauer KA, Bowling L, Byun K, Chaubey I, Chin N, Ficklin D, Hamlet A, Kines S, Lee C, Neupane RP, Pignotti G, Rahman S, Singh S, Valappil FP, Williamson T (in prep) Climate change impacts and strategies for adaptation for water resource management in Indiana. Clim Chang

Cloyd ET, Moser SC, Maibach EW, Maldonado JK, Chen T (2016) Engagement in the third US National Climate Assessment: commitment, capacity and communication for impact. Clim Chang 135(1):39-54

Cook J, Oreskes N, Doran PT, WRL A, Verheggen B, Mailback EW, Carlton JS et al (2016) Consensus on consensus: a synthesis of consensus estimates on human-caused global warming. Environ Res Lett 11: 048002

Daugherty D, Schlinkert D, Olsen-Media K, Yoon HR (2020) Attitudes and opinions about environmental issues in Indiana: 2020 survey results. Morrison Institute for Public Policy, Arizona State Univ, Phoenix, AZ. https://www.ninapulliamtrust.org/wp-content/uploads/2020/09/WEBSITE-Pulliam-Indy-Enviro-SurveyReport-2020-5-15-2020-1.pdf Accessed 07 Oct 2020

Day GJ, Chin N, Sydnor S, Widhalm M, Shah K, Dorworth L (in prep) Implications of climate change on tourism and outdoor recreation: an Indiana, USA, case study. Clim Chang

Filippelli G, Freeman J, Gibson J, Jay S, Moreno-Madriñán MJ, Ogashawara I, Rosenthal F, Wang Y, Wells E (2020) Climate change impacts on human health at an actionable scale: a state-level assessment of Indiana. USA, Climatic Change https://link.springer.com/article/10.1007/s10584-020-02710-9

Galford GL, Nash J, Betts AK, Carlson S, Ford S, Hoogenboom A et al (2016) Bridging the climate information gap: a framework for engaging knowledge brokers and decision makers in state climate assessments. Clim Chang 138:383-395. https://doi.org/10.1007/s10584-016-1756-4

Hamlet A, Byun K, Robeson S, Widhalm M, Baldwin M (2019) Impacts of climate change on the state of Indiana: ensemble future projections based on statistical downscaling. Clim Chang. https://doi.org/10.1007 /s10584-018-2309-9

Höök T, Collingsworth P, Dorworth L, Fisher B, Foley C, Hoverman J, La Rue E, Pyron M (2019) An assessment of the potential impacts of climate change on the freshwater habitats of Indiana, U.S.A. Clim Chang. https://doi.org/10.1007/s10584-019-02502-w

Houser M, Sandweiss E, Gazley B, Browning EG, Reynolds H, Shanahan J (2020) The Hoosier Life Survey. Environmental Resilience Institute, Indiana Univ, Bloomington, IN. https://eri.iu.edu/tools-andresources/hoosier-life-survey/hls-summary-report.pdf. Accessed 02 Oct 2020

Howe P, Mildenberger M, Marlon J, Leiserowitz A (2015) Geographic variation in opinions on climate change at state and local scales in the USA. Nat Clim Chang. https://doi.org/10.1038/nclimate2583

IBIS World (2019) Indiana - State Economic Profile. IBIS World, New York, NY. https://www.ibisworld. com/united-states/economic-profiles/indiana/. Accessed 02 Oct 2020

IPCC (2014) In: Core Writing Team, Pachauri RK, Meyer LA (eds) Climate change 2014: synthesis report. Contribution of Working Groups I, II and III to the Fifth Assessment Report of the Intergovernmental Panel on Climate Change. IPCC, Geneva, Switzerland $151 \mathrm{pp}$

Kirchhoff CJ, Barsugli JJ, Galford GL, Karmalkar AV, Lombardo K, Stephenson SR et al (2019) Climate assessments for local action. Bull Am Meteorol Soc 100(11):2147-2152

Lemos MC, Kirchhoff CJ, Ramprasad V (2012) Narrowing the climate information usability gap. Nat Clim Chang 2(11):789-794

McNie EC (2013) Delivering climate services: organizational strategies and approaches for producing useful climate-science information. Weather Clim Soc 5(1):14-26

NAS (2019) Making climate assessments work: learning from California and other subnational climate assessments. The National Academies Press, Washington, DC. 86 pp.https://doi.org/10.17226/25324. Accessed 02 Oct 2020

NOAA National Centers for Environmental Information (2020) Climate at a glance: statewide time series. https://wwwncdenoaagov/cag/ Accessed 02 March 2020 
PCCRC (2008) Impacts of climate change for the state of Indiana. Purdue Climate Change Research Center, Purdue University, West Lafayette, IN, USA 30 pp https://ag.purdue.edu/indianaclimate/wpcontent/uploads/2018/12/ClimateImpactsIndiana 2008-Report.pdf. Accessed 02 Oct 2020

Phillips RP, Brandt L, Polly D, Zollner P, Saunders MR, Clay K, Iverson L, Fei S (2019) An integrated assessment of the potential impacts of climate change on Indiana forests. Clim Chang. https://doi. org/10.1007/s10584-018-2326-8

Raymond L, Gotham D, McClain W, Mukherjee S, Nateghi R, Preckel PV, Schubert P, Singh S, Wachs L (2019) Projected climate change impacts on Indiana's energy demand and supply. Clim Chang https://link.springer. com/article/10.1007/s10584-018-2299-7

Reynolds HL, Brandt L, Fischer BC, Hardiman BS, Moxley DJ, Sandweiss E, Speer J, Fei S (2019) Implications of climate change for managing urban green infrastructure in Indiana. Clim Chang https://link.springer. com/article/10.1007/s10584-019-02617-0

Santos JM, Feygina I (2017) Responding to climate change skepticism and the ideological divide. Mich J Sustain 5(1):5-23

Singh S, Wachs E (2020) Projecting urban energy demand in Indiana for 2050 and 2080. Clim Chang https://link.springer.com/article/10.1007/s10584-019-02618-z

USDA NASS (2017) Census of agriculture. National Agricultural Statistics Service, United States Department of Agriculture, Washington, DC. https://www.nass.usda.gov/Publications/AgCensus/2017/Full_ Report/Census_by_State/Indiana/index.php. Accessed 02 Oct 2020

USGCRP (2017) Climate Science Special Report: Fourth National Climate Assessment, Volume I. [Wuebbles DJ, Fahey DW, Hibbard KA, Dokken DJ, Stewart BC, Maycock TK (eds)] U.S. Global Change Research Program, Washington, DC, USA $470 \mathrm{pp}$

Publisher's note Springer Nature remains neutral with regard to jurisdictional claims in published maps and institutional affiliations. 